\title{
EL TEATRO DE LA ESPAÑA CONTEMPORÁNEA (1868-1936)
}

\author{
Rocío Arana* \\ $M^{a}$ Teresa Santa María ${ }^{* *}$ \\ María Simón ${ }^{* * *}$
}

\begin{abstract}
RESUMEN: Los años que van de 1868 a 1936 suponen no solo grandes cambios en la historia contemporánea de España, sino también un momento de gran renovación en su escena teatral. En este artículo nos proponemos dar un panorama global sobre un periodo teatral poco conocido y que supone el puente desde unas propuestas anteriores - neoclásicas, románticas y más tradicionales - hasta una dramaturgia más renovadora y que explica, en buena parte, la consecución a lo largo del siglo XX de una manera diferente de entender y hacer teatro en España. Se presenta un estudio más detallado de la dramaturgia de tres autores que caracterizan muy bien sendas perspectivas teatrales en la España de ese momento: José Echegaray, Benito Pérez Galdós y Joaquín Dicenta. Y, por último, se demuestra la importancia de poder digitalizar las piezas teatrales de esta época para su conocimiento y estudio.
\end{abstract}

PALABRAS CLAVE: Teatro español. Periodo entre revoluciones. Realismo. Alta comedia. Drama social.

\section{Teatro nuevo para tiempos nuevos}

Así define Ruiz Ramón esos tiempos convulsos y llenos de cambios que van desde la Revolución de 1868 hasta el inicio de la guerra civil de 1936, donde se producen en la escena española un cambio de tendencias y una renovación de propuestas que habilitaron a la dramaturgia española para entrar con buen paso en las Vanguardias y propuestas más innovadoras que encontramos en el siglo pasado y que continúan en este.

\subsection{La Restauración y el final del teatro decimonónico}

\footnotetext{
*Universidad Internacional de la Rioja, La Rioja, España. E-mail: rocio.arana@unir.net

* Universidad Internacional de la Rioja, La Rioja, España. E-mail: tsantafernandez@yahoo.es

*** Universidad Internacional de la Rioja, La Rioja, España. E-mail: maria.simon@unir.net
}

\section{(cc) EY-NC-ND}

Esta obra está licenciada com uma licença Creative Commons.

Texto Digital, Florianópolis, Santa Catarina, Brasil, v. 11, n. 2, p. 111-127, jul./dez. 2015. ISSNe: 1807-9288. 
La etapa cronológica en la que nos encontramos nos sitúa en dos vertientes: la Restauración y el final del teatro decimonónico. En la conjunción de ambas aparecen varios dramaturgos importantes.

En primer lugar, se encuentra la figura de Echegaray y su, denominado por los críticos, drama-ripio. Su obra dramática se caracteriza por estar cargada de falsedad; lo real y humano queda completamente al margen en la misma. Según Ruiz Ramón "el dramaturgo tiene el genio innegable de inventar situaciones dramáticas constitutivamente falsas" (1996, p. 351).

Entre los autores predominantes de esta época, contamos también con el dramaturgo Dicenta. Su figura ha quedado muy relacionada con el drama social, en el que ha colaborado tanto con obras escritas en verso (El suicidio de Werther - La honra y la vida) como en prosa (Luciano) cuyo eje central gira en torno a temas éticos.

Cierra el grupo de escritores importantes, Benito Pérez Galdós que escribió un total de veinte obras de las cuales, siete, proceden de adaptaciones de novelas. Este es el caso de obras como: La loca de la casa, El abuelo, Casandra, Gerona, Zaragoza y Doña Perfecta. Esta trasposición de novelas al teatro hace que muchos críticos señalen que Galdós no supo separar ambos géneros, lo que hizo que en el teatro aplicara muchas de las técnicas empleadas en sus novelas.

Dentro de esta época, encontramos a otros tres dramaturgos. Es el caso de Cano, Sellés y Felíu y Codina. Sobre estos dramaturgos, Ruiz Ramón comenta: "estos tres autores teatrales representan, cada uno con personalidad propia, algunos de los aspectos principales del mediocre teatro que abastecía los escenarios de fin de siglo" (1996, p. 358). El teatro de dichos escritores se caracteriza por estar muy influenciado por el estilo que Echegaray empleaba en sus obras.

\subsection{Del 98 a la generación de los años 20}


En palabras de Serge Salaün, "hacia 1900, habrá mucha crisis de todo tipo, pero el teatro españoles indiscutiblemente uno de los teatros más nutridos de Europa" (2005, p. 9). El periodo que comprende las dos primeras décadas de la nueva centuria es "indiscutiblemente uno de los más complejos, efervescentes, porque todos los géneros o fórmulas teatrales coexisten, pujan por subsistir o imponerse" (2005, p. 8).

Una pléyade de autores pueblan estos años. Francisco Ruiz Ramón dedica las primeras páginas de su volumen sobre el teatro del Siglo XX a Benavente, al que elogia por su ingenio y al que a la vez acusa de esterilidad, aburguesamiento y cinismo; a Carlos Arniches, del que valora su contribución al "género chico" pero mucho más su tragedia grotesca, siguiendo a Pedro Salinas, y a los hermanos Álvarez Quintero, que durante su tiempo gozaron de gran fama ante el público pero se ganaron la enemistad de autores como Valle- Inclán por ofrecer un retrato amable, idealizado y aparentemente falto de crítica social de la sociedad andaluza y que el profesor Ruiz Ramón denomina como "realismo naturalista ingenuo" (1996, p. 49). Posteriormente cayeron en el olvido y fueron ninguneados por autores como Víctor García Ruiz para ser en los últimos tiempos rescatados por algunos estudiosos.

En estos primeros años del siglo XX siguen las propuestas de géneros y de obras que habían sido la tónica hasta ese momento. Ruiz Ramón destaca en Eduardo Marquina (1879-1946) tres grupos diferentes de obras: "drama histórico en verso, comedia realista en prosa y drama rural en verso" (1986, p. 65), aunque sea sobre todo conocido por sus dramas históricos, escritos, bien antes de la Primera Guerra Mundial - La hija del Cid (1908), Doña María la Brava (1909), En Flandes no se ha puesto el sol (1910) o Las flores de Aragón (1914) - o a partir de 1930 como El monje blanco (RUIZ RAMÓN, 1986, p. 66). Otros autores que se apuntaron a esa moda del teatro histórico en verso serían: Francisco Villaespesa (1877-1936), Luis Fernández Ardavín (1891-1962), Enrique López Alarcón (18911948), Fernando López Martín (1882-1942?) o Joaquín Montaner (1892-1957). 
Ni siquiera los hermanos Machado, Manuel (1874-1947) y Antonio (1875-1939,) escapan a la creación de piezas en verso, como comenta Ruiz Ramón al hablar de sus obras escritas en colaboración (1986, p. 71-76). Destacará también la moderna visión que Antonio Machado tiene sobre el teatro, "especialmente sobre la acción dramática y sobre la función del monólogo y del aparte". Para un conocimiento y análisis más pormenorizado de su obra se pueden consultar los recientes estudios de la investigadora Rosa Sanmartín, quien destaca su evolución desde recreaciones de obras clásicas hasta propuestas más acordes con su época, como aparecen en Las adelfas (1928) o El hombre que murió en la guerra (1941) (SANMARTÍN, 2010).

Frente a esa estética que conserva dejes de dramas románticos o realistas del siglo XIX, surgen también por esos años lo que Ruiz Ramón ha catalogado como labor de "innovadores y disidentes" (1986, p. 77). Dentro de esta consideración se incluirían algunas de las obras teatrales de Miguel de Unamuno (1864-1936), para quien había que educar los gustos del público, por lo que su desnudez estructural y reducción estética - La venda y El otro - van acompañadas de versiones de mitos clásicos como Fedra o Medea y de su inclusión en la dramaturgia europea de autores como "Claudel, Eliot, Anderson, Cocteau, Giraudoux, parte de Anouilh, etc." (RUIZ RAMÓN, 1986, p. 79). También se ha destacado la importancia de Ramón del Valle-Inclán (1866-1936), como precursor de la Vanguardia escénica en España (OLIVA y TORRES MONREAL, 2014, p. 319) en una trayectoria que va "desde sus primeros dramas casi románticos: El yermo de las almas (1908)", "El marqués de Bradomín (1905), Cuento de abril (1909) y Voces de gesta (1911)" (p. 326) hasta sus esperpentos - Luces de bohemia o Divinas palabras, de 1920 - , pasando por comedias modernistas inspiradas en la commedia dell'arte como La Marquesa Rosalinda (1912).

Idéntico camino, del drama naturalista de Entre llamas a farsas y propuestas más innovadores - El hijo pródigo, El señor de Pigmalión - sigue Jacinto Grau (18771958), dramaturgo que toma como modelos teatrales a Shakespeare, Pirandello, 
Shaw, D'Annunzio y Hebbel (PERAL, 2009, p. 28-29). Y autores que destacan por otros géneros literarios, como Ramón Gómez de la Serna (1888-1963) o José Martínez Ruiz, "Azorín", (1873-1967) nos ofrecen la perspectiva de ese teatro de "conato" (RUIZ RAMÓN, 1986, p. 160) y "de renovación y vanguardia", respectivamente (LÓPEZ MONZO).

\section{Estudio de tres autores elegidos}

Dentro del proyecto BETTE de digitalizar las obras teatrales españolas que conforman este periodo, el grupo GHEDI (Grupo de Humanidades Digitales) de UNIR (Universidad Internacional de La Rioja) empieza su andadura con tres autores muy representativos de esa escena de finales del XIX y principios del XX. Nos referimos a Echegaray, Galdós y Dicenta.

\subsection{Alta comedia: José Echegaray (1832-1926)}

Echegaray fue un personaje polifacético que despertó pasiones y violentos rechazos por igual: fue ingeniero, científico político... y dramaturgo. El mejor matemático español del XIX según muchos, Académico de Ciencias Exactas, Físicas y Naturales en 1866, emprendió esta última carrera ya en la madurez, a pesar de sentir atracción hacia la escena desde su juventud más temprana, apunta Sánchez Ron (2004, p. 601). En ella cosechó una cierta antipatía por parte de la crítica, aunque esto debe afirmarse con algún matiz, como luego se verá, y un indudable éxito ante el público que le llevaría a ganar un sillón en la Real Academia de la Lengua a finales del siglo y el premio Nobel en 1904; si bien corrieron algunas turbias sospechas de que este galardón era debido más a motivos políticos que literarios. Como muestra de su vida azarosa y polifacética valga este botón: El libro talonario, su primera obra estrenada en el año 1874 fue escrita en París en el fragor de un azar político, durante un obligado y breve exilio tras la revolución del 1868. 
En esta misma línea afirman Carmen Meléndez Onrubia y Julián Ávila Arellano que Echegaray era ante todo un científico y un político, y cuando ya mayor se decide por la versificación y el teatro, lo hace con una técnica científica buscando una fórmula dramática adecuada que repitió a lo largo de su más de medio centenar de composiciones (1987, p. 39-40). Entre estas se encuentran El gran galeoto (estrenada en1881); O locura o santidad (1876), El loco Dios (1900) y A la orilla del mar (1893).

No terminan aquí las paradojas De ideología liberal, José Echegaray era kantiano y krausista, pero su obra es, en gran parte, heredera de la dramaturgia de la "Alta comedia" (SEMPER, 2005, 43-44). Y sus coetáneos realistas critican sus dramas por estar apegados a los moldes románticos, por buscar el pathos por encima de cualquier otra motivación teatral, por llenar la escena de truculencias y, de nuevo en palabras de Semper, por manipular a su público "por la fascinación, la ilusión, la identificación o el interés apasionado por el desenlace" ( 2005, p. 45). Esto es lo lógico cuando nos encontramos, de nuevo según SAMPER, ante "un teatro de emociones en vez de un teatro de ideas" (2005, p. 43). Algo que percibió con acierto un crítico coetáneo, Fermín Herrán (1880) que escribe una ponderada monografía sobre el dramaturgo.

Si tantas recriminaciones mereció Echegaray entre los dramaturgos de la época, ¿por qué triunfa su drama de este modo en las salas de este momento? El público quería entretenimiento y emoción, y encontraba ambos ingredientes en él, como señalan Meléndez Onrubia y Ávila Arellano. La burguesía finisecular impone la "rentabilidad utilitaria" en el teatro. Los autores viven o intentan vivir del teatro (al igual que lo hizo Lope de Vega en su tiempo, no hay que olvidarlo, y siempre pendiente del gusto de sus espectadores). Por eso crean para estrenar y triunfar, hacer dinero.... Por eso escriben cada obra para una compañía o una actriz en concreto, como María Guerrero, por quien Echegaray sintió fascinación y dependencia a la vez. (MELÉNDEZ ONRUBIA y ÁVILA ARELLANO, 1987, p. 33). El público exige una obra de entretenimiento, y siente predilección por formas expresivas heredadas de las traducciones francesas de Víctor Hugo y Dumas, 
patéticas y exageradas (p. 35). Sin embargo, SALAÜN defiende al público de esta época, afirmando que no es tan adocenado como se dice. Y, para apoyar su tesis, achaca a Benavente cinismo y a Unamuno paternalismo cuando arremeten contra los gustos y exigencias de sus espectadores. (2005, p. 10).

Hoy el nombre literario de Echegaray está casi olvidado, no así su contribución a la matemática, y Francisco Ruiz Ramón no le muestra simpatías: lo tilda de risible y patético e inventa para él la temible expresión "Drama ripio" (1996, p. 350). Pero, ¿y si no fuera tan unánime el rechazo de la intelectualidad de la época? En efecto, lo que más puede interesarnos en esta figura es la controversia que suscita: una brecha que no sólo se abre entre crítica y público sino entre los mismos estudiosos. En una postura claramente antagónica a Ruiz Ramón, Serge Salaün defiende que este evidente éxito de público se puede comprender, ya que el autor finisecular "aporta ingredientes auténticamente teatrales, una propuesta escénica menos convencional. Por lo menos, con Echegaray, el público no se aburre" (2005, p. 11). Meléndez Onrubia y Ávila Arellano, más conciliadores, comentan que su teatro no es peor que otros como Zorrilla, mejor valorados (1987, p. 37), y recuerdan que los dramas de Galdós son un fracaso (1987, p. 28).

Tampoco es, como ya adelantábamos, rigurosamente cierto que todos sus correligionarios abominasen del teatro de Echegaray. Librada Hernández ha estudiado la postura moderada de Galdós y la clara fascinación de Clarín. La tesis de esta autora es que tanto Clarín como Pardo Bazán y Galdós pretenden enriquecer su prosa con rasgos teatrales, y para ello se fijan en él. En el citado artículo se afirma que Galdós admira el mecanismo teatral de Echegaray, pero no su contenido: "Galdós admira en Echegaray la fuerza de construcción dramática. Más que nada, advierte en algunas obras una naciente tendencia a un realismo escénico, que mostraba dotes para llevar al teatro por un nuevo rumbo. No obstante, Galdós pensaba que el aparatoso dramaturgo tenía que cambiar las convenciones escénicas y ajustarse al nuevo estilo realista" (HERNÁNDEZ, 1992, p. 103). 
Aún más decidido a favor de Echegaray aparece Clarín, que "insiste en que su contribución a la escena española representa un paso positivo en la regeneración del teatro" (HERNÁNDEZ, 1992, p. 96). El autor de La Regenta ve a Echegaray como un reformador que trasgrede las barreras establecidas por sus contemporáneos pero mirando hacia el pasado, incorporando de nuevo la mitología del drama de capa y espada. Echegaray reúne unas ideas políticas muy queridas para Clarín, ya que son las suyas propias, con una querencia por el verso y una clara inspiración clásica que, si para algunos caía en el peligro de quedar en una mera copia, para otros podía ser inspiración e incluso renovación divergente. No en vano, Echegaray admiraba a Calderón de la Barca y versionó y refundió algunas de sus obras (por ejemplo, Semíramis o la hija del aire, 1896).

Los temas del teatro echegariano oscilan entre "el teatro histórico-legendario romántico y el drama de tesis" (HODDIE, 1989, p. 18). El castigo, la muerte, la locura y el deshonor como desenlaces trágicos por un amor desgraciado: "El protagonista de un drama de Echegaray casi indefectible e irremediablemente marcha hacia la desgracia, o sea, hasta la tragedia" (HODDIE, 1989, p. 19). Un ejemplo sería Valentina, protagonista de $A$ la orilla del mar y heroína romántica creada para mayor esplendor de la actriz María Guerrero: enamorada del ateo Leoncio, renuncia a él cuando este intenta deshonrarla.

El artificio formal de Echegaray varía desde el verso ripioso de El gran galeoto a una prosa más verosímil y natural en obras como $A$ la orilla del mar. En esta se perciben también matices de una ironía que hará reír a carcajadas al público, merced al personaje de Don Baudilio, enfermo crónico, y a Don Trifón y Don Crescencio, meteorólogo y sismógrafo respectivamente. En ellos vertió Echegaray su vena cómica, aprovechando seguramente sus conocimientos científicos.

En conclusión, nos encontramos ante una disparidad de opiniones que convierten a José Echegaray en un personaje con aristas, con matices, nada plano: un autor que merece la pena estudiar con mayor detenimiento. 


\subsection{Dramas realistas: Benito Pérez Galdós (1843-1920)}

Dentro de los dramas realistas, una de las figuras predominantes es la de Benito Pérez Galdós. El interés y la admiración que ha suscitado, este autor, en muchos críticos, ha llevado a revisar en los últimos años toda la producción teatral del mismo, lo que ha permitido comprobar que, en este género literario, Galdós, también tuvo un papel importante. Además dicha revisión ha revelado que, como afirma Fernández (2003, p. 2001), sus dramas son elementos claves no sólo para entender la trayectoria estética y personal de su autor, sino también para comprender más profundamente parte de los nuevos rumbos del teatro y de la compleja sociedad española entre 1890 y 1920.

Muchos son los estudios y trabajos que existen de este autor y su teatro desde finales del siglo XX. Sin embargo, llama la atención la escasez de ediciones críticas que existen de sus obras teatrales. Sólo se cuenta con las de Realidad, La loca de la casa, La de San Quintín, Voluntad, Electra y Alma y vida y todas ellas tienen un acceso muy restringido.

Si nos centramos en la figura de Galdós como autor de teatro, hay que fijar el año de 1892 como el de su estreno. Sin embargo, al parecer, su aproximación a este terreno ya venía de mucho tiempo atrás, concretamente, de sus primeros años de aprendizaje como escritor, en los que ya se ve que no está satisfecho por la situación en la que se encontraba el teatro de la época. Sea antes o después de 1892, cuando Galdós tiene su contacto con el teatro, existen críticos, como Arencibia, quien señalan que su llegada al teatro se produce "en la plenitud de su madurez artística; cuando su fama era ya extensa y cuando su prestigio como novelista garantizaba el interés del público y le abría las puertas de los escenarios" (2010, p.178). A lo largo de su trayectoria como autor teatral cosecha tanto triunfos como fracasos que le llevan, en muchas ocasiones, a mantenerse en silencio. Sin embargo, fuese cual fuese la reacción de los espectadores, todos los estrenos de sus obras eran esperados con mucho interés por el público. 
Cuando Galdós trabaja en sus obras dramáticas considera que es necesario, dadas las circunstancias de la época, crear un teatro social que influya más en los espectadores. Para él, era necesario reflejar la realidad en la que se encontraba la sociedad del momento y esto es lo que predomina, desde diferentes perspectivas, en sus obras teatrales. A este respecto, Rubio (1998, p. 125) señala que los conflictos de los dramas galdosianos son los que él apreciaba en la sociedad española, que de un lado se sentía impelida hacía actitudes mentales modernas, pero por otro no acababa de desprenderse de viejos modos de comportamientos periclitados.

En sus obras, tiene muy en cuenta el tipo de público al que van dirigidas la mismas, lo que hace que en el diálogo de los personajes eliminen ciertas expresiones que puede, en cierta medida, incomodar al espectador. Por el contrario, nada ni nadie le impide reflejar su opinión sobre las diferentes clases sociales que constituyen la sociedad de la época. Para ello, se sirve de los personajes de sus obras que, muchas veces, se "autodefinen" ellos mismos y otras muchas, es la valoración del resto de personajes la que retrata la figura del protagonista central de la obra. Normalmente, los personajes o tienen problemas con la circunstancias del momento o el problema son ellos mismos. Sobre el teatro galdosiano, Fernández afirma que "su amplia veintena de textos dramáticos responden a dos objetivos fundamentales: su intención de ejemplaridad moral y su implícita o explícita vinculación con España, una España en decadencia moral y material" (2003, p. 2008).

Para finalizar, la producción dramática de Galdós ha sido clasificada por los críticos desde diferentes puntos de vista: según los personajes, el tema central de la obra, la fecha de estreno, etc. Si nos centramos en esta última, se ve que, a su vez, se pueden crear dos grupos: a) dramas de finales del siglo XIX: Realidad (1892); La loca de la casa (1893); Gerona (1893); La de San Quintín (1894); Los condenados (1894); Voluntad (1895); Doña Perfecta (1896) y La fiera (1896) y b) dramas de principios del siglo XX: Electra (1901); Alma y vida (1902); Mariucha 
(1903); El abuelo (1904); Bárbara (1905); Amor y ciencia (1905); Pedro Minio (1908); Zaragoza (1908); Casandra (1910); Celia en los infiernos (1913); Alcestre (1914); Sor Simona (1915); El tacaño Salomón (1916); Santa Juana de Castilla (1918). De todas estas obras, según Shaw (1996, p.148) "tuvo cuatro éxitos resonantes: La de San Quintín, Doña Perfecta, Electra y El abuelo, siendo las dos últimas, en todos los conceptos, obras importantes del drama moderno español".

\subsection{Un teatro éticamente comprometido: Joaquín Dicenta (1863-1917)}

Este dramaturgo de finales del siglo XIX ha sido recientemente reivindicado, gracias a estudios como los de la profesora Leticia MCGRATH (2004) y de Jesús Andrés ZUECO (1991), aunque también tuvo un momento de auge durante la valoración que del teatro social se realizó en los años setenta del pasado siglo (MAINER, MAS FERRER).

Aunque pueda parecer el típico ejemplo de autor una sola obra, Juan José, su dramaturgia es extensa y toca diferentes géneros, no solo el llamado "teatro social" que le ha otorgado la fama. De esta forma, estrena su primer drama, El suicidio de Werther: obra dramática, el 23 de febrero de 1888, en el Teatro de la Princesa de Madrid y con Rafael Calvo como protagonista. Le siguen las representaciones de La mejor ley: obra dramática (1889), Los irresponsables: drama en tres actos y verso (1890), Honra y vida (1891), El Duque de Gandía: drama lírico en tres actos y un epílogo en verso música de los (1894) con música de Antonio Llanos y Ruperto Chapí para una trama conectada "con la dramaturgia de Echegaray" (IBERNI, 1995, p. 200). Y estrenará Juan José, el 25 de octubre de 1895 en el Teatro de la Comedia de Madrid, cuyo pretendido carácter social ha sido cuestionado recientemente (FERNÁNDEZ INSUELA, 1997, p. 13-28) o matizado respecto al que había esos años en la escena europea (LÓPEZ CRIADO).

A la misma, siguen otros estrenos de muy variada índole: zarzuelas o dramas líricos como Curro Vargas en 1898 o Juan Francisco (1904), Entre rocas (1905); 
comedias en prosa como El león de bronce (1900) o De tren en tren: comedia en un acto inspirada en un cuento francés (1902), La conversión de Mañara (1905), Amor de artistas (1906), Lorenza (1907), La confesión (1908), Los tres maridos burlados: enredo en tres cuadros y un prólogo, en verso inspirado en la novela de Tirso de Molina y escrita en colaboración con Pedro de Répide (1909); monólogos como El tío Gervasio (1900) y Marinera (1907); o dramas que siguen el corte social como El señor feudal (1896), Aurora: drama en tres actos y prosa (1902), Daniel (1907) y El crimen de ayer: drama en tres actos y en prosa (1908) o que traducen o versionan obras de otros autores, como sucede con El místico: drama en cuatro actos y en prosa, traducción de una obra de Santiago Rusiñol (1913) o su pieza póstuma La promesa, "leyenda lírica-dramática en cinco jornadas, inspirada en un cuento de Gustavo A. Bécquer" (1917).

La obra dramática de Joaquín Dicenta destaca por varias razones fundamentales. En primer lugar, por el retrato de los usos, costumbres y problemas sociales que acuciaban a la España entre finales del siglo XIX y principios del siglo XX (BOTTIN, VALLADARES). En segundo lugar, porque ese realismo y denuncia social abrieron la puerta a un tipo de teatro que no se había representado hasta la fecha en nuestro país y que tendrá continuidad en dramaturgos del siglo XX hasta los años treinta (OLIVA y TORRES MONREAL, 2014, p. 324). En tercer lugar, porque en él se ejemplifican muy bien todos los géneros que imperaban en la escena en su tiempo, donde las piezas musicales, comedias y dramas históricos alternaban de vez en cuando con alguna obra donde "los contenidos éticos juegan un papel predominante" (RUIZ RAMÓN, 1996, p. 363). Y, en cuarto y último, porque refleja muy bien la forma de hablar de su época, en concreto de las clases más humildes.

\section{A modo de conclusión}

Conviene señalar que, aunque la Biblioteca Digital Hispánica, de la Biblioteca Nacional de España, y la Biblioteca Virtual Cervantes guarden en sus catálogos algunas obras de este importante periodo teatral, faltan muchos autores y piezas 
destacadas. De ahí la importancia de la tarea que el proyecto BETTE que el grupo GHEDI de UNIR se propone llevar a cabo.

\section{SPANISH CONTEMPORARY THEATER (1868-1936)}

ABSTRACT: The years from 1868 to 1936 not only witnessed deep changes in contemporary Spanish history, but also meant a moment of great renewal in the Spanish theatre of the time. In this paper we aim to provide a general overview of a little-known period which meant the link between some former proposals - neoclassicism, romanticism and more traditional approaches and a more groundbreaking type of drama. To some extent, this period accounts for the establishment during the $20^{\text {th }}$ century of a new paradigm in both the understanding and performance of Spanish theatre. We provide a detailed study of the theatrical work of three playwrights that perfectly represented Spanish theatre at that time: José Echegaray, Benito Pérez Galdós, and Joaquín Dicenta. Finally, the importance of digitising the plays of this period for research purposes is proved.

KEYWORDS: Spanish Theatre. Inter-revolution Period. Realism. High Comedy. Social Drama.

\section{Bibliografía}

ANDRÉS ZUECO, Jesús. La obra dramática de Don Joaquín Dicenta Benedicto. UNED, 1991.

ARENCIBIA, Carmen Yolanda. Galdós. El teatro y su poética. En GUTIÉRREZ, Raquel y RODRÍGUEZ, Borja (coords.). Desde la platea, estudios sobre el teatro decimonónico. Santander: PUbliCan, 2010. p. 177-190.

BOTTIN, Béatrice. La dialéctica de las clases sociales y su representación en Juan José de Joaquín Dicenta. In URRUTIA GÓMEZ, Jorge. De esclavo a servidor: Literatura y sociedad (1825-1930). Madrid: Biblioteca Nueva, 2014, p. 77-87.

DICENTA, Joaquín. Juan José. Madrid: Cátedra, 2000. 
ECHEGARAY, José. .A la orilla del mar: comedia en tres actos y un epílogo, en prosa. Madrid: Sociedad de Autores Españoles, 1895.

ECHEGARAY, José. Semiramis o la hija del aire (segunda parte): drama en tres jornadas y en verso por Pedro Calderón de la Barca. Arreglado y difundido por José Echegaray. Madrid: Evaristo Odriozola, 1896.

ECHEGARAY, José. Conferencias sobre física. Madrid: Imp. Gaceta de Madrid 1906/9 y $1910 / 16$.

ECHEGARAY, José. Recuerdos. Madrid: Ruíz Hermanos, 1917.

ECHEGARAY, José. Teatro escogido. Madrid: Aguilar, 1964. Prólogo de Armando Lázaro Ros. Muchas de ellas están en el portal virtual Cervantes.

ECHEGARAY, José. El gran galeoto. Madrid: Cátedra, 1989. Edición de James Hoddie.

FERNÁNDEZ, Antonio. Galdós y el drama social. En HUERTA, Javier. Historia del teatro español (Del siglo XVIII a la época actual). Madrid: Gredos, vol. 2, 2003. p. 2001-2030.

FERNÁNDEZ INSUELA, Antonio. Sobre el nacimiento del teatro social español y su contexto. Monteagudo: Revista de literatura española, hispanoamericana y teoría de la literatura, n. 2, p. 13-28, 1997.

FRANCO, Andrés. El teatro de Unamuno. Madrid: Ínsula, 1971.

GUTIÉRREZ, Raquel; RODRÍGUEZ, Borja (Coords.). Desde la platea, estudios sobre el teatro decimonónico. Santander: PUbliCan, 2010. p. 177-190. 
HERNÁNDEZ, Librada. Clarín, Galdós y Pardo Bazán frente al teatro de José Echegaray. Anales de literatura española, n. 8, p.95-108, 1992.

HERRAN, Fermín. Echegaray: su tiempo y su teatro. Madrid: Fortanet, 1880.

IBERNI, Luis G. Ruperto Chapí. Madrid: Ediciones del ICCMU, 1995.

LÓPEZ CRIADO, Fidel. El teatro de Joaquín Dicenta: la otra revolución social. Arbor: Ciencia, pensamiento y cultura, n. 752, p. 1197-1207, 2011.

LÓPEZ MOZO, Jerónimo. El teatro de Azorín; entre la renovación y la vanguardia. Melilla: UNED, 1998. Disponível em: <. http://www.cervantesvirtual.com/nd/ark:/59851/bmcc5418>. Acceso em: 16 abril 2015.

MCGRATH, Leticia. Joaquin Dicenta: Spain's Forgotten Dramatist. Juan de la Cuesta, Hispanic Monographs, 2004.

MAINER, José Carlos. Literatura y pequeña burguesía en España: (notas 18901950). Madrid: Edicusa (Divulgación Universitaria. Serie Literatura, 42), 1972.

MAS FERRER, Jaime. Vida, teatro y mito de Joaquín Dicenta, Alicante, Instituto de Estudios Alicantinos, Diputación Provincial (Publicaciones del Instituto de Estudios Alicantinos. Serie I, 39), 1978.

MELÉNDEZ ONRUBIA, Carmen y ÁVILA ARELLANO, Julián. El neorromanticismo español y su época. Epistolario de José Echegaray a María Guerrero. Anejos de la revista Segismundo, n. 12. Madrid: CSIC (Consejo Superior de Investigaciones Científicas, 1987.

OLIVA, César, TORRES MONREAL, Francisco. Historia básica del arte escénico. Madrid: Cátedra, 2014. 
PEDRAZA JIMENEZ, Felipe B y RODRIGUEZ CACERES, Milagros. Manual de literatura española. VII. Época del Realismo. Pamplona: Cénlit, 1983, p. 251-258.

PERAL VEGA, Emilio. Introducción. In GRAU, Jacinto. El señor de Pigmalión. Madrid: Biblioteca Nueva, 2009, p. 9-104.

ROMERO, Leonardo (Coord.). Historia de la Literatura española. Siglo XIX (2), Madrid: Espasa Calpe, 1998. p. 122-131

RUBIO, Jesús. El teatro de Pérez Galdós: tradición y nuevos caminos. En RUIZ RAMÓN, Francisco. Historia del Teatro Español. Siglo XX. Madrid, Cátedra, 1986.

RUIZ RAMÓN, Francisco. Historia del Teatro Español. Siglo XX. Madrid, Cátedra, 1986.

RUIZ RAMÓN, Francisco. Historia del Teatro Español (Desde sus orígenes hasta 1900). Madrid: Cátedra, 1996.

SALAÜN, Serge. Autopsia de una crisis proclamada. SALAÜN, Serge; RICCI, Evelyn; SALGUES, Marie (Eds). La escena española en la encrucijada (18901910). Madrid: Fundamentos, 2005, p. 7-23.

SAMPER, Edgard. Orden y desorden en el teatro burgués finisecular: la herencia de la "alta comedia" en la obra de José Echegaray. In SALAÜN, Serge; RICCl, Evelyn; SALGUES, Marie (Eds). La escena española en la encrucijada (18901910). Madrid: Fundamentos, 2005, p. 43-57.

SÁNCHEZ RON, José Manuel. José Echegaray: entre la ciencia, el teatro y la política. Arbor, n. 707-708, noviembre-diciembre, p. 601-688, 2004. 
SANMARTÍN, Rosa. La labor dramática de Manuel y Antonio Machado. Granada: Ediciones Mágina, 2010.

SHAW, Donald. Historia de la literatura española. El siglo XIX. Barcelona: Ariel. 1996.

VALLADARES REGUERO, Aurelio. Los problemas sociales de la minería linarense de comienzos de siglo en la obra literaria de Joaquín Dicenta. Boletín del Instituto de Estudios Giennenses, n. 171, p.117-143, 1999.

Texto recebido em: 19/10/2015. Texto aceito em: 11/12/2015. 